\title{
JOSEF ZEIDLER: IT IS IMPOSSIBLE TO DICTATE THE PASSION
}

\author{
Josef Zeidler is the CEO of Hilti for the Czech and Slovak Republic. In his interview \\ for Central European Business Review, he talks especially about leading employees \\ and how managing people connects with profitability.
}

I've read that you are guitar player and I also saw a motorcycle in your office. So these are the main things that you are passionate about?

These two have completely different meaning. Yes, guitar has been my passion already for many years. I used play in a band when I was younger and we played mostly rock 'n' roll. Even thou I was attending only classical guitar classes. My teacher at that time was the famous guitar player Eva Matějková and I remember I enjoyed it very much. However I do not play regularly in a band at the moment but, I am still passionate about it.

That old motorcycle, you saw in my office is another thing. That's not connected directly with the passion. I just bought it from one of our customer and it is connected with a very nice story. Nevertheless the bike is here on purpose, because when we are hiring new people, they always come to my office for a short interview and everybody react the same as you did: Ohh you have an old bike here? Is that your passion? Why is the bike here? And I say, look, there is not only the bike in this office; you can see also flower here. This example with a bike and flower represent the complexity and multi dimensionality of our company. And that is what every employee in our company should understand.

The bike in my office represents the ground rules, major things and processes that our customers and our employees are valuing the Hilti Company for. For instance as an employee, we ensure that you will always get your salary on time, that the IT system always works. That we deliver quality products to our customers, that the Hilti centres in the Czech Republic, Slovakia and all over the world opens at 7 o'clock as it is written on the entrance doors or website. These are very strict rules, which must work like a machine in order to deliver the promise. On the other hand there is a flower in my office. The flower represents the people. People are not machines and we do not expect them to act and work like machines. People are just people. People are sometimes happy, sometimes unhappy; from time to time they can't work and deliver due to illness or have complicated family issues etc. but we know that our people can deliver above stated things. Therefore we have to take care of them, as we have to take care of the flowers. The flower in my office sometimes needs more light; sometimes I have to put it into a shadow if the sun is too strong; sometimes I have to water it more, sometimes less etc. The bike and the flower in my office should help our people to understand that our company culture is based on caring for people. On the other hand we demand the performance and success, which is represented by the bike.

In fact, the bike is fully functional and I ride it from time to time. I do not own any other bike therefore I cannot say that riding a bike is my passion. The bike is there mostly for demonstration of the company culture. Before the bike, I had a big pendulum clock and instead of the flower there was a parrot. It was always combination of thing that demonstrated the necessity of care and perfect functionality.

It's known, that you personally really care about people. Why is that? Does it make a difference when figures are so important nowadays?

Yes you are right, figures are important, but the people are even more important in these days due to the insecurity on the market and negative outlook for the future. No 
one can really predict when the next crisis will come and I am sure that the ups and downs will come even more often. We do not expect to have a stable future or growth. Our company had very successful years in the past but as any other company on the market we were hit by the latest crisis and also had very difficult times. And I must proudly say that the year 2013 was very successful, which is spectacular, if you take into consideration that construction market has negative growth. The success and the great figures in 2013 and were mainly due to our people.

Why am I caring for people that much? Because it's the biggest value I and our company have. We have high quality products; great systems, excellent processes and nice shops etc. ... But that you will only achieve when you employ and assign right people to a right place and give them opportunity to develop themself. People are able to deliver great results only when they see and understand why they do what they do. The success of our company is because we are teaching our people to not look only for short term results, but look for a lifelong career. It sounds might sound little bit like fairy-tale, but we are happy that we can offer and provide our employees with great opportunity to stay with us and move in their careers. The system can be compared to a bus; I call it the Hilti bus. In the Hilti bus there are number of seats (positions) and if somebody does not perform well or does not like what is he doing at that moment, then we change his seat. But if someone doesn't like the Hilti bus than...thank you very much and goodbye. But overall, we are happy to have all these people on the bus and we spent a lots time and effort to figure out their right seat.

\section{How did it happen that you give such importance to your employees? I can see in other companies that it is usually all about figures and exact outcomes. How it actually happened, that you are aware of this issue?}

Let me correct you. You said the others companies are only concerned about numbers and key - performance figures. But we also have clear targets and ambitions that we would like to achieve. Without that we would not be on the market. Hilti has a good brand and good products but on the other hand we have to make profit because without being profitable everything would just disappear. Simple saying, we also have to be able to finance all the operations and bring the profit to the owners at the same time.

Regarding the second part of your question, how I realized and how I got this attitude. I am practising this model/attitude since the very early stage of my carrier

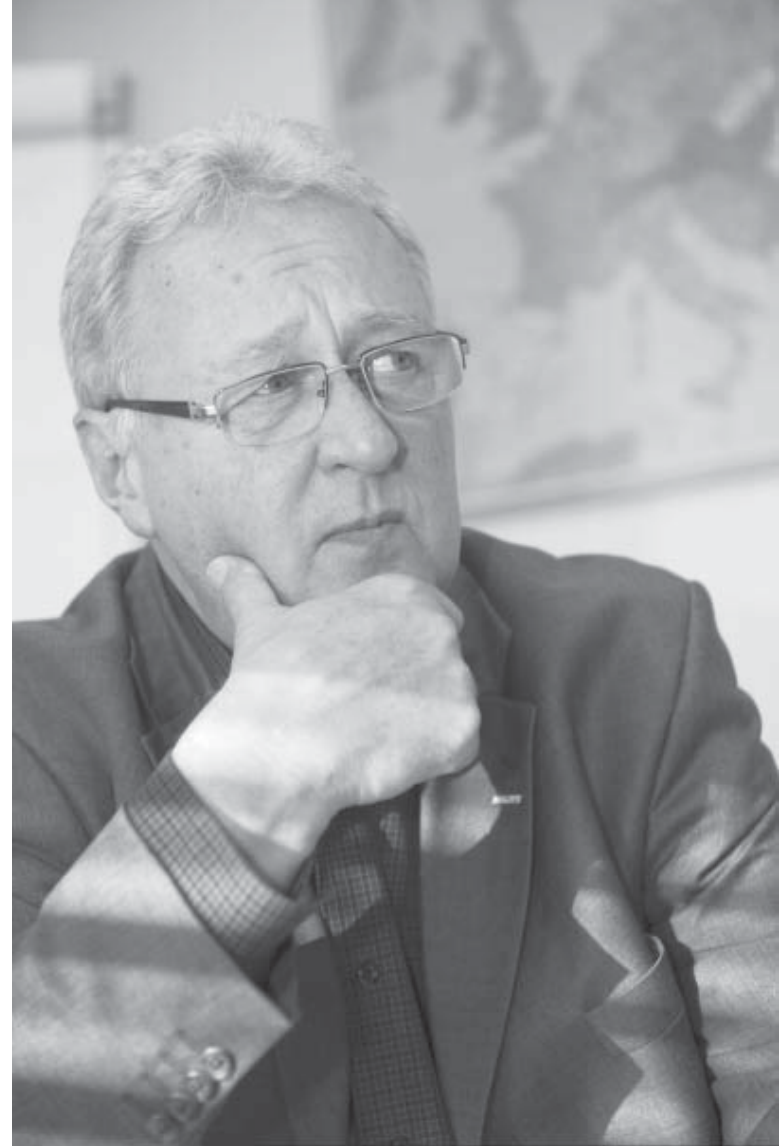

Photo: Jan Branč

and now people are talking about me as a prototype of successful manager which is concerned about people. I have started in Hilti almost 30 years ago and I went through several positions, I started as a regular sales man, then I moved to a position of sales manager, little bit of marketing and so on, now I'm general manager. Already more than 25 years I am in the leading position. I have realized very quickly, that in order deliver the team results, you have to manage your team. Only by managing the team you became a leader of the team. There is a significant difference between leader and manager. I'm not only the figures oriented, but I'm also so called "soft" oriented. This "soft" orientation is very important and is closely connected with empathy and understanding of what people needs are. For instance, you have to always focus on what can you personally do to help your people to make their business easier or to help themselves to develop. Develop doesn't mean that we have to talk only about positive things but sometimes it is necessary to speak out loud the things we don't like or are negatively accepted by the others. Moreover 
I found out that sometimes you have to let things just go. This might sound weird but I am living example that it can work.

When I take a look back, I could not even imagine that I could be able to be at the position where I am at the moment. I was lucky that I always had great leaders who led me and believed that I am able to do what I did and what I do now. I'm trying to do the same as a leader now. I am always trying to lead my team in the way I think they should lead their people. It sounds relatively simple, but there is a lot of work with people in it.

\section{What would you recommend to the people in top positions in other companies? How should they start to treat their people?}

There are a lot of similar patterns at all the high management positions. But the results depend on how effectively you work with people. One of the most important question which you have to ask yourselves is: do the people you lead trust to/in you? Moreover it is also necessary to think about is how to efficiently measure the trust? This is not only about feelings it is more complex and today it can be captured ant transform into hard data too. In Hilti, we regulary have internal research in the company; it is called GEOS - Global Employee Opinion Survey. Every single Hilti market organisation in the world, it means 25000 people all around the globe, answers a specially designed, anonymous questioner. The results are analysed by the external company, which prepare a summary for each organization and each team. In that questioner we also measure trust in the leaders. This is a very strong management instrument. For instance we can perfectly see spaces for improvement within our management team

However GEOS gives is precious insight in what is going on in our company, but in order to get complete picture about the company itself and its position on the employer market we are regularly participating overall market researches done by external research companies. It is basically similar to what we are doing internally but these external researches help us to compare ourselves with best companies on the market as an employer. We compare ourselves with the best companies on the market we analyse why these companies are so successful and then we take action. For example lately we figured out that we have quite low gender employment ratio. It might be due to the nature of the type of the business that we are active in but we have already started some activities to improve that. The main issue was the retention of employees after the maternity leave. In the past, we offered career before the maternity leave and we had limited number of positions that could be offered to employees that would come back from the maternity leave. This is going to change. People are in our longterm strategy.

In similar researches we can often hear words like performance, excellence, global team and all kinds off similar expressions. But those are usually empty words. You are an exemplar company, always in top 10 or even top 5 employers of the year, so you really mean all these expressions. Why is that? And why it doesn't usually work in other companies?

I can't really say. Recently, I have visited one of our customer and they had a sign on their entrance doors: "In our house, there is an open communication". I was asking myself would I write this on my front doors. In case that such an open communication would be in place, I would not put it there. Moreover I as a visitor am assuming that the communication is not as open as it is written there and that sign was just a warning. I don't know, but it made me smile.

We are also developing and moving forward. A few years ago we also had some internal communication issues. I remember that even general managers had difficulties to understand the formulations of the global strategies. But things have changed and maybe the recent crisis has helped in the field of communication. I remember that before the crisis the people could not understand the word instability. The business world is now different world after the crisis and we have to react on it. In order to survive on the market we have to be very fast and very flexible now. The flexibility is the name of the game. Now, most of the time we deeply analyse the market patterns and observe the changes and we are trying to react on the signals of the change as fast as possible. This is something very new. This hasn't been here before the crisis.

You try to be transparent to your employees. On the other hand, it's very difficult on the market these days and it's really tough in your industry but you are still here and...

And we will be, we will stay! (laughs)

... so, what is your approach to the customer and the market? How do you make things work when there are such terrible issues not only here in the Czech Republic but in whole Europe?

We have a very unique business model all over the world. In our business model we have various channels that we use to reach the customers. Our biggest differentiation 
towards our competitors and one of our main channel is the direct sales, we have 7000 salesmen worldwide, who are in contact with current and potential customers every day. If you take into account that each sales man is approximately making eight to ten visits a day, that gives us huge amount of information and immediate feedback on the actions that we are doing on the market. Moreover this channel helps us to solve other issues that would be difficult to handle other way. For instance, it is fast and effective in solution for possible complaints.

As we launch new products, we also launch new channels within our business model. For example, several years ago, we introduced Hilti Online, fully functional e-shop, and this year we will introduce its new generation. The new generation of Hilti Online is already in place in USA and Germany and we belive that the percentage share of business that is done online will significantly increase, currently we have $16 \%$ and our target is $50 \%$. The online business is very trendy and for us very profitable.

In addition, we have the customer service, that helps our customers to reach us over the phone and manage the business and get all the information. Then we also have Hilti Centres all over the world where every customer can come and experience the products. The business model is extensive and very difficult to copy. Therefore I can say that we do not have much of the relevant competitors. We have a huge $\mathrm{R} \& \mathrm{D}$ department and the company is investing huge amount of money into product development. This year the investment will be more than 300 mio $\mathrm{CHF}$ and the result you will see in our stores which are already full of great products. We are probably the only company within our segment that covers the whole chain: the $\mathrm{R} \& \mathrm{D}$, production, logistics, sales marketing etc. and we are very proud of that. This gives us huge potential for differentiation.

\section{This system must be pretty...}

...expensive. Yes it is.

\section{A very interesting thing about this is that in general, you are not doing much different things than others but somehow, you're doing everything better than them. What makes the difference? Is it the people, the system...?}

It's definitely all about the people. Currently I'm reading Steve Jobs' biography and it's very interesting and inspirational. Moreover I can see some similarities in the company culture with current Hilti Company. One of those "big" words to describe people's attitude that leads to success is passion. But the question is how do you manage the passion within the team? You cannot dictate the passion or give it by order. That never works. You can only try to transmit your passion to your customers, colleagues or your team. It makes much bigger difference if you talk about the product with a real passion then just plainly describe the features of the product. There is a huge necessity for constant self-reflection, basically you have to be constantly asking yourself questions about what makes you passionate in order to make it passion. For instance is it the product that creates passion? Is it the corporate culture that we have, is the fair salary system, is it the working place, the car policy etc.? And then you think what should be changed in order to create passion. The people have to be satisfied in order to deliver. For instance in our company we don't have meetings on Monday mornings and Friday afternoons because you have meeting on Monday at eight, that means that you have to be at work on Sunday evening. We respect all these things in order to create passionate people.

We completely understand that our employees do many other things, except their work. Then we passionately support the team spirit, people in our company play hockey or football together, regularly go out for drink or a dinner together. The team spirit and the other after-work activities are very important. Like I have said people are not machines. In order to make people passionate and moreover successful business the people that do the business have to feel the good atmosphere and see the future-orientation of the company. Even if someone is having a bad day or month you have to show the support and offer help. It is important that people at work stick together. It's like a big family.

You are also very successful from the regional point of view, not only in the Czech Republic or Slovakia but this whole cluster. What do you think about this region? What is different here? And what is the future of the region?

What is the future of this region? That's a difficult question. I'm originally German, I lived in Munich for most of my whole life but I was born in Mariánské Lázně so I am Czech as well and I love this country. The Czech Republic and other countries in this region are like a bridge between the east and the west. And to be honest I see such a bridge as something very important and in some way special. A bridge is always connecting two places which are relatively far away from each other. I think that the bride works perfectly now. The nice thing about it is that most of the things are somewhere in between the west and east level, for instance services. That gives us a huge space and opportunity for 
improvement which can be done just by observing the neighbours in the west and east on the other hand the region must keep its traditions and not just blindly copy everything from the others. I have a feeling that some people forget about this.

\section{Could you name some of the strong qualities of the people from this region?}

At the moment, we have 26 people that were hired either in Czech or Slovak and moved abroad and are on the top management positions within the company Hilti. We have people for instance in Hong Kong, Dubai Australia, UK etc. and what is very interesting is that a bigger part of our Russian management team also comes from Czech Republic of Slovak and recently we have established great cooperation with Russia. I see a great potential in this region and also in countries located further to the west like Ukraine or Russia. Russia is now becoming one the biggest market for Hilti world-wide. It is simple there, basically if you bring a good quality product that supports the development of the nation, you can build a very successful business. Moreover there are a lot of highly educated people, who appreciate to work in a strong, stable so called "western" company and these people are much easier to find there or in this region than in the western countries.

There are stereotypes that Italians are interested in design, Germans are far more systematic... What would you say is typical for this region?

Again, that's a very difficult question but what I admire is that the Czech Slovak, Hungarian, Ukrainian and Baltic citizens are mostly very keen on constant education. I don't see that in the west. And honestly that is the right attitude, the willingness to learn, to move and to change? As I said flexibility is the name of the game. Moreover I like the unique sense of humour you have to live here to really understand it.

My personal observation is that Czechs and Slovaks have more flexibility and I think that they will manage changes better in future The reputation of this country is quite negative in the foreign media because of the current unstable political situation, corruption but I hope for change.

\section{Why is the marketing centre for the CEE region} here?

We have our marketing centre here because we have the highest levels of competence here. Again it is about the people that we have here. Additionally Prague is very much convenient for travelling and for logistics.

\section{And because of you?}

...look, I won't be in the company forever, as I won't be alive forever. I have a great people around me and that is what makes the Prague office successful. Moreover the level of integration, respect to others and all that we've already talked about leads to the successful and profitable job that we are doing here.

Author

Tomáš Poucha

Marketing Institute

Faculty of Business Administration University of Economics, Prague

Nám. W. Churchilla 4, 13067

Prague 3, Czech Republic tpoucha@mkti.cz 